\title{
COMPARISON OF SHOULDER PAIN, DISABILITY AND RANGE OF MOTION IN DIABETIC AND NON-DIABETIC PATIENTS WITH FROZEN SHOULDER
}

\author{
Sobia Younas $^{\prime \otimes}$, Arooj Fatima' $^{\prime}$
}

\begin{abstract}
OBJECTIVE: To compare the shoulder pain, disability, and range of motion in diabetic and non-diabetic frozen shoulder (FS) patients.

METHODS: This cross-sectional study was conducted from December 2018 to June 2019 on 210 clinically diagnosed patients of FS. Study included equal number $(n=105)$ of diabetes mellitus (DM) patients and non-diabetic patients, ranging in age from 35 to 65 years. Non-probability purposive sampling was used to assemble the data from various private and government hospitals of Lahore. A plastic goniometer and shoulder pain and disability index (SPADI) tool was used to extract data. Data was analyzed through SPSS v.21.0.
\end{abstract}

RESULTS: In 210 patients with frozen shoulder, the mean age was $53 \pm 10.3$ years \& $48 \pm 9.9$ years in DM \& non-diabetic patients respectively $(p=0.94)$. Frequency of male \& female patients was $43(40.95 \%)$ and $62(59.05 \%)$ in diabetic group $(n=105)$ \& $38(36.19 \%)$ and $67(63.81 \%)$ in non-diabetic group $(n=105)$ respectively. Mean body mass index was $25.6 \mathrm{I} \pm 2.14$ \& $25.39 \pm 2.16$ in diabetic \& non-diabetic patients respectively $(p=0.32)$. Mean SPADI score was $66.69 \pm 13.20$ in diabetic and $63.34 \pm 15.01$ in non-diabetic group $(p=0.191)$. Regarding motion range at shoulder, mean degrees of flexion, external rotation, internal rotation and abduction were $103 \pm 23.07,30 \pm 11.20,34 \pm 11.970$ \& $101 \pm 25.55$ in diabetic patients as compared to $113 \pm 29.61,39 \pm 14.34$, $40 \pm 15.77 \& 109 \pm 33.80$ in non-diabetic patients respectively $(p=\leq 0.05)$.

CONCLUSION: There is no significant difference in severity of pain and disability in diabetic \& non-diabetic patients with frozen shoulder. However, range of motion was significantly better in non-diabetic patients as compared to diabetic patients having frozen shoulder.

KEY WORDS: Diabetes Mellitus (MeSH); Frozen shoulder (Non-MeSH); Shoulder Pain (MeSH); Range of Motion, Articular (MeSH).

THIS ARTICLE MAY BE CITED AS: Younas S, Fatima A. Comparison of shoulder pain, disability and range of motion in diabetic and non-diabetic patients with frozen shoulder. Khyber Med Univ J 2020;12(3):22I-4. DOI: 10.35845/kmuj.2020.19483.

\section{INTRODUCTION}

$\mathrm{D}$ iabetes mellitus (DM) is a metabolic disease associated with various microvascular and macrovascular complications. Apart from neuropathic pain, musculoskeletal pain is also common in diabetic patients.' Diabetic patients have higher (27.5\%) prevalence of shoulder disorders as compared to $5 \%$ in general medical patients. ${ }^{2} \mathrm{DM}$ is often commonly associated with "frozen shoulder" (FS) or "adhesive capsulitis", a painful joint disorder that cause pain, stiffness and limited mobility of shoulder joint. ${ }^{3,4}$ According to a study, the combined estimated prevalence of frozen shoulder and diabetes mellitus is $71.5 \%$ and about half of frozen shoulder has been previously diagnosed with type I and || diabetes. The lifetime risk of evolving a frozen shoulder in diabetic patient is about $10 \%$ to $20 \%$, with a point prevalence of $4 \% .^{5}$ Some studies have shown that this increase in prevalence of adhesive capsulitis in diabetic patients may be related with
I. University Institute of Physical Therapy, Faculty of Allied Health Sciences, The University of Lahore, Lahore, Pakistan. Email『: sobiayounas02@gmail.com Contact \# : +92-302-7591888

Date Submitted: July 16, 2019 Date Revised: June 06, 2020

Date Accepted: July I I, 2020

age, gender and duration of diabetes. ${ }^{6}$ Frozen shoulder rarely occurred before the age of 40 and have a peak incidence between 40 to 60 years of age. It affects women slightly more common than men. ${ }^{7}$ Risk factor for frozen shoulder include female sex, age greater than 40 years, DM, previous trauma, HLA-B27 positivity and prolong immobilization of glenohumeral joint. ${ }^{8}$ Patients with FS are mostly presented with debilitating pain and tenderness around the anterior shoulder. Pain can be induced by daily activities and sudden movement. Patients also have difficulty in sleeping on affected side and often render "sickening" pain if the arm is dragged in any direction." There is shoulder restricted range of motion (ROM) in all directions particularly external rotation, flexion and abduction. Patients have distinct functional disability and reduced quality of life. ${ }^{10}$

The treatment of FS includes operative and non-operative management. The non-operative management include patient education, physical therapy, drugs and electrical stimulation. Physical therapy intervention includes the use of therapeutic modalities and other procedures that reduce the pain. Exercises and movement are an important part of treatment to increase the ROM of shoulder joint." Some studies reported that frozen shoulder tend to be more persistent with diabetes and are difficult to be treated as compared to the idiopathic frozen shoulder patients. ${ }^{8}$ 
TABLE I: DEMOGRAPHIC DETAILS AND SHOULDER EVALUATION MEASURES OF PATIENTS WITH FROZEN SHOULDER

\begin{tabular}{|l|c|c|c|}
\hline \multicolumn{1}{|c|}{ Variables } & $\begin{array}{c}\text { Diabetic patients } \\
\text { with FS* }(\mathbf{n}=105)\end{array}$ & $\begin{array}{c}\text { Non-diabetic patients } \\
\text { with FS }(\mathbf{n}=105)\end{array}$ & P-value** \\
\hline Age (years) & $53.3 \mathrm{I} \pm 10.35$ & $48.47 \pm 9.99$ & 0.94 \\
\hline BMI*** & $25.6 \mathrm{I} \pm 2.14$ & $25.39 \pm 2.16$ & 0.32 \\
\hline SPADI**** score & $66.69 \pm 13.20$ & $63.34 \pm 15.01$ & $0.19 \mathrm{I}$ \\
\hline Degree of Shoulder Flexion & $103 \pm 23.07$ & $113 \pm 29.6 \mathrm{I}$ & 0.030 \\
\hline $\begin{array}{l}\text { Degree of Shoulder External } \\
\text { Rotation }\end{array}$ & $30 \pm 11.20$ & $39 \pm 14.34$ & 0.013 \\
\hline $\begin{array}{l}\text { Degree of Shoulder Internal } \\
\text { Rotation }\end{array}$ & $34 \pm 11.97$ & $40 \pm 15.77$ & 0.05 \\
\hline $\begin{array}{l}\text { Degree of Shoulder } \\
\text { Abduction }\end{array}$ & $101 \pm 25.55$ & $109 \pm 33.80$ & 0.006 \\
\hline
\end{tabular}

Few studies had discussed about the disability in FS patients while other evaluated the pain and disability level in diabetic patients, but minimum literature has compared the shoulder pain, disability and ROM in diabetic and non-diabetic patients with frozen shoulder therefore, this study is designed to find if there are any difference exist in shoulder pain, disability and ROM among diabetic and non-diabetic patients with FS.

\section{METHODS}

This cross-sectional study was conducted on two groups (diabetic and non-diabetic) from December 2018 to June 2019. The approval was taken from ethical committee of University Institute of Physical Therapy, Univsersity of Lahore, Lahore. After informed written consent, a total of 210 patients were enrolled in this study. Sample size was estimated by using Open $\mathrm{Epi}^{12}$ where $\sigma \mathrm{I}=15.5, \sigma 2=16$, $\Delta=6, z|-\beta=80, z|-\alpha / 2=1.96(95 \%$ confidence level), $\mathrm{K}=\mathrm{I}$ which calculated $\mathrm{n} \mid=105, \mathrm{n} 2=105 .{ }^{13}$ Nonprobability sampling technique was used to collect data from University of Lahore Teaching Hospital, Lahore, Sheikh Zayed Hospital, Lahore and District Headquarter Hospital, Okara.

Group I included diabetic subjects with age of 35 to 65 years, clinically diagnosed frozen shoulder, and having limited shoulder range of motion; whereas Group 2 included non-diabetic subjects with age of 35 to 65 years, clinically diagnosed frozen shoulder, and having limited shoulder range of motion. Subjects with previous trauma, injury, fracture, cardiovascular diseases and psychological illness were excluded from both groups. Both groups were matched for age, gender and BMI. Extreme pain, significant decrease in shoulder range of motion especially external rotation are the hallmarks of frozen shoulder. Existence of these features in subjects was the diagnostic for inclusion in this study.

The outcome measure tool used was shoulder pain and disability index $(\text { SPADI) })^{14}$ which include 13 items to access pain and disability and was scored from 0 to 10. An average score was then taken and converted to percentages that ranged between 0 to $100 \%$. A plastic goniometer was used to measure the ROM. Active ROM was measured in supine position within pain free range for shoulder flexion $\leq 120^{\circ}$, external rotation $\leq 40^{\circ}$, abduction $\leq$ $110^{\circ}$ and internal rotation $\leq 50^{\circ}$. The collected data was analyzed using statistical package for social sciences (SPSS) version 2I. Descriptive statistics like mean \pm standard deviation were determined for quantitative data while the qualitative data were presented in the form of frequency and percentages. Independent sample T-test was used to compare the groups and $\mathrm{p} \leq 0.05$ was considered to be significant statistically.

\section{RESULTS}

Out of 210 patients with frozen shoulder, 105 (50\%) were diabetic and 105 (50\%) were non-diabetic. Frequency of male \& female patients was 43 (40.95\%) and $62(59.05 \%)$ in diabetic group $(n=105) \& 38(36.19 \%)$ and $67(63.81 \%)$ in non-diabetic group $(n=105)$ respectively. The mean age of DM patients was $53 \pm 10.3$ whereas the mean age of non-diabetic patients was $48 \pm 9.9$.

Mean body mass index was $25.6 \mathrm{I} \pm 2.14$ \& $25.39 \pm 2.16$ in diabetic \& nondiabetic patients respectively $(p=0.32)$. Mean SPADI score was $66.69 \pm 13.20$ in diabetic and $63.34 \pm 15.01$ in nondiabetic group $(p=0.191)$. Data regarding motion range at shoulder including degrees of flexion, external rotation, internal rotation and abduction in diabetic and non-diabetic patients is given in Table I.

\section{DISCUSSION}

This cross-sectional study showed that shoulder pain and disability were common in both diabetic and nondiabetic groups and were insignificant difference was noted in statistics for shoulder pain and disability between the both the groups $(p=0.191)$. However, diabetic patients had more limited joint mobility as compared to non-diabetic frozen shoulder patients. There was significant difference in the shoulder range of motion among frozen shoulder patients with or without diabetes.

The age of patients with FS was between 35 to 65 years and mean age was $53.31 \pm 10.35$ years (diabetic group) and the mean age in non-diabetic patients was $48 \pm 9.9$ years. Dias $R$, et al. conducted a study that show the peak age of FS is 56 which was quite similar to our findings. ${ }^{15}$ Studies have reported that FS is unlikely in patients of less than 40 years old. ${ }^{7.8}$ Patients aging more than seventy years are more prone to develop rotator cuff tears or glenohumeral osteoarthritis instead of adhesive capsulitis. $^{16}$

Frozen shoulder patients with diabetes indicate high score of pain and disability but no statistical difference was noticed among frozen shoulder patients with or without DM. A cross-sectional study was carried out by Haig $A J$ and his 
coworkers to compare the pain and disability level in diabetic and nondiabetic frozen shoulder patients. They used the similar tool and concluded that no remarkable difference was present in patients with or without DM. ${ }^{13}$ However, another cross-sectional study conducted on diabetic patients visiting a diabetic health center, reported that diabetic patients have greater pain and disability than non-diabetic patients which did not support the results of this study. ${ }^{17}$ They suggested that this difference was due to the long duration of diabetes mellitus and complications of diabetes.

Present study also showed that the diabetic patients had more restricted ROM especially shoulder abduction, external rotation and flexion as compared to non-diabetic patients. Abate, et al. measured the passive ROM for shoulder abduction along with flexion and concluded that range of motion is 2 to $14 \%$ decreased in DM patients as compared to patients without DM. ${ }^{18}$ Appropriate ROM of shoulder is required to fulfill tasks of daily life such as grooming, overhead activities and personal care, and this decrease in the shoulder range of motion may impede essential activities of daily life. ${ }^{19}$ A study suggested that the restricted joint motion may be associated with age and duration of diabetes and the shoulder pain and disability may be associated with diabetic complications and poor glycemic control. ${ }^{20}$

It is believed that the restricted joint mobility is due to uncontrolled aggregation of advanced glycation end products. Some studies suggest that simple exercises may be helpful to regain the ROM of shoulder particularly shoulder flexion and external rotation and to reduce or prevent the destructive changes in diabetic patients.

The sample size of the study was small. The results could have been more precise with larger available population and sample size. This study did not discuss about the development and progression of shoulder impairment in diabetic patients as this was a crosssectional study. Further studies should be conducted to explain the factors that may be associated with the impairments in upper extremity in diabetic patients and to find out that exercise can be helpful to impede these impairments.

\section{CONCLUSION}

There is no significant difference in severity of pain and disability in diabetic $\&$ non-diabetic patients with frozen shoulder. However, range of motion was significantly better in non-diabetic patients as compared to diabetic patients having frozen shoulder.

\section{REFERENCES}

I. Molsted S, Tribler J, Snorgaard O. Musculoskeletal pain in patients with type 2 diabetes. Diabetes Res Clin Pract 2012 May;96(2): 135-40. DOI: 10.1016/j.diabres.2011.12. 022.

2. Hsu CL, Sheu WH. Diabetes and shoulder disorders. J Diabetes Investig 20I6;7(5):649-5I. DOI: |0. I | | |/jdi. |249|.

3. Smith LL, Burnet SP, McNeil JD. Musculoskeletal manifestations of diabetes mellitus. $\mathrm{Br} J$ Sports Med 2003;37(I):30-5.DOI: I0.1136/ bjsm.37.I.30.

4. Schiefer M, Teixeira PFS, Fontenelle C, Carminatti T, Santos DA, Righi LD, et al. Prevalence of hypothyroidism in patients with frozen shoulder. J Shoulder Elbow Surg 2017;26(I):49-55. DOI: 10.1016/j.jse.2016.04.026.

5. Robinson CM, Seah KTM, Chee YH, Hindle P, Murray IR. Frozen shoulder. J Bone Joint Surg $\mathrm{Br}$ 2012;94(I):I-9. DOI: 10.1302/ 030I-620X.94BI.27093.

6. Thomas SJ, McDougall C, Brown IDM, Jaberoo MC, Stearns A, Ashraf $R$, et al. Prevalence of symptoms and signs of shoulder problems in people with diabetes mellitus. J Shoulder Elbow Surg 2007;16(6): 748-5I. DOI: 10.1016/j.jse.2007. 02.133.

7. Uppal HS, Evans JP, Smith C. Frozen shoulder: A systematic review of therapeutic options. World J Orthop 20I5;6(2):263-8.DOI: 10. 5312/wjo.v6.i2.263.
8. Massoud SN, Pearse EO, Levy O, Copeland SA. Operative management of the frozen shoulder in patients with diabetes. J Shoulder Elbow Surg 2002; II(6):609-13. DOI: I0.1067/mse.2002.12730I.

9. Whelton C, Peach CA. Review of diabetic frozen shoulder. Eur J Orthop Surg Traumatol 2018; 28(3):363-7I. DOI: 10.1007/s 00590-0। 7-2068-8.

10. Cho C-H, Jung S-W, Son E-S, Hwang I-S. Sleep status and quality of life in patients with frozen shoulder. J Korean Orthop Assoc 2012;47(3): 205-I0. DOI: I0.4055/jkoa.20I 2. 47.3.205.

II. Wong PL, Tan HC. A review on frozen shoulder. Singapore Med J 20I0;5I(9):694-7.

12. Rosner B. Fundamentals of Biostatistics. $5^{\text {th }}$ edition. USA: Cengage Learning, Inc; 2000.

13. Uddin MM, Khan AA, Haig AJ, Uddin MK. Presentation of frozen shoulder among diabetic and nondiabetic patients. J Clin Orthop Trauma 2014;5(4):193-8. DOI:I0. 1016/j.jcot.2014.09.008

14. Roach KE, Budiman-Mak E, Songsiridej N, Lertratanakul Y. Development of a shoulder pain and disability index. Arthritis Care Res 199|;4(4): I43-9.

I5. Dias R, Cutts S, Massoud S. Frozen shoulder. BMJ. 2005;33I(7530): |453-6. DOI: I0.1|36/bmj.331. 7530.1453.

16. Mezian K, Coffey R, Chang KV. Frozen Shoulder. In: StatPearls [Internet]. Treasure Island (FL): StatPearls Publishing; 2020 Jan-. [Accessed on: July II, 2020]. Available from URL: https://www. ncbi.nlm.nih.gov/books/NBK 482162/

17. Shah KM, Clark BR, McGill JB, Mueller MJ. Upper extremity impairments, pain and disability in patients with diabetes mellitus. Physiotherapy 2015;10I(2): 147-54. DOI: $10.1016 / j$.physio.2014. 07.003.

18. Abate M, Schiavone C, Pelotti P, 
Salini V. Limited joint mobility (LJM) in elderly subjects with type II diabetes mellitus. Arch Gerontol Geriatr 201 I;53(2):135-40. DOI: 10.1016/j.archger.2010.09.011.

19. Silverstein JH, Gordon G, Pollock
$\mathrm{BH}$, Rosenbloom AL. Long-term glycemic control influences the onset of limited joint mobility in type I diabetes. J Pediatr 1998;132(6): 944-7.DOI:10.1016/S0022-3476 (98)70388-9.
20. Laslett LL, Burnet SP, Redmond CL, McNeil JD. Predictors of shoulder pain and shoulder disability after one year in diabetic outpatients. Rheumatology (Oxford). 2008; 47(I0): I583-6. DOI: 10.1093/ rheumatology/ken333.

\section{AUTHORS' CONTRIBUTIONS}

Following authors have made substantial contributions to the manuscript as under:

SY: Conception \& study design, acquisition of data, drafting the manuscript, critical review, final approval of the version to be published

AF: Analysis and interpretation of data, drafting the manuscript, final approval of the version to be published

Authors agree to be accountable for all aspects of the work in ensuring that questions related to the accuracy or integrity of any part of the work are appropriately investigated and resolved.

CONFLICT OF INTEREST

Authors declared no conflict of interest GRANT SUPPORT AND FINANCIAL DISCLOSURE NIL

\section{DATA SHARING STATEMENT}

The data that support the findings of this study are available from the corresponding author upon reasonable request

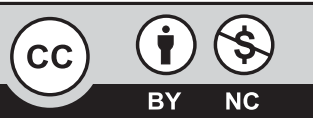

This is an Open Access article distributed under the terms of the Creative Commons Attribution-Non Commercial 2.0 Generic License.
KMUJ web address: www.kmuj.kmu.edu.pk

Email address: kmuj@kmu.edu.pk 